\title{
Effective Communication as Catalyst of Developmental Local Government and Rural Development amid Threats of Overpopulation
}

Naledzani Rasila and John Mudau

\begin{abstract}
South Africa's population has risen from S40.5 million in 1996 to 44.8 million in 2001 and to 51.77 in 2011. Africans are in majority making $79.2 \%$ of the whole population. About $22.3 \%$ of blacks have received no schooling with the unemployment rate of the blacks at $28.1 \%$. Most of these unemployed and uneducated blacks are found in rural areas. This compelled government to introduce Developmental Local government. Developmental Local government refers to the layer of public service that has the capacity to deliver and account to the people in a responsive, accountable, effective and efficient manner. It is also described as a sphere that encourages community participation in matters of governance and developmental initiatives. However, Developmental Local government is hindered by continuous growth of population which is likely to lead to overpopulation. Overpopulation is characterised by lack of basic resources such as water and food. Developmental Local government on the other hand is expected to deliver on these needs. Lack of fulfilment of goals of Developmental

effective communication between local government and community members. Although population growth is not attributed only to high birth rate, governments around the continent have introduced measures to encourage healthy reproductive life. However, this needs community members that are selfmotivated to be active participants in government initiatives. This is not achievable as there is an indication of lack of effective communication. This paper's main focus is the provision of effective communication model at local sphere which will see community members working together with government on matters of their own development including initiatives to preserve limited resources amid the challenges of overpopulation. This paper is based on the qualitative study on effectiveness of communication in Mutale local municipality on the enhancement of Developmental Local government and rural development. The study indicated weaknesses and suggests for the development of new model of communication.
\end{abstract} Local government is attributed to lack of

Keywords: Effective Communication, Local Government, Rural Development, Overpopulation, Service Delivery, South Africa. 


\section{INTRODUCTION}

Until recently, birth rates and death rates were about keeping the population stable. People had many children but large number died before the age of five. The Industrial revolution came with great advances in science and technology which then reduced death rates. Industrial revolution came with increased food production, improved public health and medical technology. These improvements got spread throughout the world lowering rates and improvement of quality of life for most people. However, the population of South Africa seems to be rapidly growing as indicated in results or census 2011 released this year where South African population is at about 52 million.

Rapid human population growth has a variety of consequences. It has been noted that population grows fastest in the world's poorest countries. High fertility rates have historically correlated with poverty and high childhood mortality. Overpopulation and poverty have long been associated with increased death and disease. Overpopulation can be described as a condition of having more people than can live on a certain part of the world in comfort, happiness and health and still leave the space for future generation.

Lack or poor improvement of living condition of people defeats the purpose Developmental Local Government. Developmental Local Government is a government that takes community members along while providing better living condition through community participation.

However, it can be argued that all governments around the country came to realise the importance of creation of awareness on matters of population control in particular focusing on birth control. Action plans and strategies have been developed to increase public understanding of how rapid population growth limit chances for meeting basic needs. There is an importance of the spirit of open communication and empowerment of individual women and men on matters of health care, family planning and women's education at community level.

In this paper, there will be an example of birth control awareness by different countries. It is important to note that it can be argued that despite different communication strategies, models and systems used to create awareness there is still lack of effective communication model to address this challenge and also to enhance effectiveness of Developmental Local Government. It is argued that rapid population growth and overpopulation results in negative impact on rural development.

This papers focuses on lack of effective communication around the world, impact of population growth on developmental local government, role of 
effective communication in realising Development Local Government, involvement of community members in matters of governance and introduce a proposed Effective Communication Model to enhance Developmental Local Government and Rural Development which will assist in empowering community members to take part on matters of over-population control. It is based on qualitative study conducted in Mutale local municipality, Limpopo Province in South Africa which indicated that there is a communication gap between the municipality and the community it serves and that this becomes a challenge on the realisation of the objectives of Developmental Local government and rural development.

\section{APPROACHES TO CONTROL OVERPOPULATION}

There are a number of factors contributing to population growth. These range from migration, asylum seeking, birth and death rates. Every country has a way to put these factors under control. One major control is birth control. Birth control is also known as contraception or fertility control. This refers to methods or devices used to prevent pregnancy. This seems to be the easiest method to embark on as it needs effective communication. Effective communication refers to communication process in which community members become active in identifying their challenges, identify interventions and be part of implementation, monitoring and evaluation of the whole process.

Methods to control birth include hormonal where contraceptives inhabit ovulation fertility, intrauterine devices and sterilization. This papers argues more for behavioural and fertility awareness methods. Behavioural methods involve regulating the timing or method of intercourse to prevent introduction of sperm into the female reproductive tract either completely or when the egg is present. Fertility awareness is calendar based contraceptive method where un-protective sex is restricted to a woman's least fertility period. Government, particularly at local level should also emphasize other scientific methods such as use of pills and condoms. Awareness and adherence to the methods demands for effective communication.

The "one- child policy" implemented in 1979 in China was meant for reduction of unintended pregnancies and as a mechanism for birth control. This prevented over 400 million births but did not completely deal with the challenge of unplanned birth and population growth. Awareness of contraceptives is nearuniversal among married women in India. They however experience a challenge of inability to access the choice of contraceptive method. In 2011, just one out of five Pakistani women aged 15 - 49 used birth control. In America, contraceptives 
had been available for free under the National Health Services since 1974 and $74 \%$ of reproductive age women use some form of contraceptives. South Africa, Zimbabwe and Botswana are said to have successful family planning programmes but other central and Southern African countries continue to encounter extreme difficulties in achieving higher contraceptive prevalence and lower fertility for a wide variety on compounding reason. However, as indicated in Census 2011 results released in 2012, the population of South Africa has gone high compared to the past results (Stats SA, 2012). It can be argued therefore that there is a need for effective communication that will involve all community members, men and women in matters of population control hence introduction of the proposed model for effective communication for the enhancement of the objectives of Developmental Local Government. Lack of effective communication between government institutions and community members they serve is a global challenge.

\section{GLOBAL CHALLENGE OF LACK OF EFFECTIVE COMMUNICATION BETWEEN GOVERNMENT AND ITS LOCAL COMMUNITIES}

The importance of effective communication in promoting successful implementation of developmental initiatives cannot be questioned. For example, Dudley (1997: 601) argues that the communication gap between government and community members have potential of hindering economic successes. He laments the existence of a considerable communication gap between development agencies and communities.

Lu (2009:4) reports that communication gaps in economic activities impact negatively on development initiatives. He argues that China needed effective communication to build its internal and external images. Portrayal of a poor image by communities within the country is a sign of a communication gap between government and its people. In 2008, the economy of China was damaged in the international arena, resulting in both its internal and international reputation being dented. According to Lu (2009:4), lack of effective communication and inadequate knowledge of international communication skills needed to relate with her own stakeholders was likely to be the major reason for this status quo.

Sawer (2009) also contends that a communication gap exists between the government and the people in Australia. He attributes this to the traditions of secretive government on the one hand and high levels of community distrust on the other. When there is distrust between the government and the communities 
it is hard for people to believe in the government programmes such as those focusing on the control of overpopulation.

According to Hurskainen (1993:26) the situation described above are caused by Government believing that they are custodians of correct policies and possess appropriate knowledge for developing people's living conditions. Most governments strive to address the ignorance that communities have of the programmes including population control and opportunities that they can take advantage of to improve their livelihoods. In Tanzania, this ignorance is called Unjinga. In an attempt to strengthen the flow of information between the government and grassroots communities, it was erroneously argued that Unjinga should be replaced with effective acquisition of formal education.

As Olutimayin (2002:237) points out, effective communication between government and its people is crucial even in the health industry. The Health for All System introduced in Nigeria between 1993 and 1998 led to the establishment of the Primary Health Care System. The goals of the Health for All System could not be achieved because effective communication channels among health facilities, Districts and community members were non-existent. Moreover, it was recognised then that communication between decision makers in the urban offices and implementers in rural areas needed attention. Although a lot of efforts have been made the situation has not completely changed. It can be argued therefore that there will be difficulties in the realisation of universal access to developmental initiatives such as the access to reproductive health services, population health and development of sustainability.

In their report on Service delivery protests in South Africa( 2009: ii), the Department of Cooperative Governance and Traditional Affairs (CoGTA) and Parliament of the Republic of South Africa highlighted the existence of a communication gap between municipalities and communities that hinders the realization of Developmental Local Government. This, as indicated in the same report CoGTA, hinders the realisation of Developmental Local Government.

In South Africa, the government has developed a plethora of developmental initiatives including family planning which is aimed not only at controlling population growth but also transmission of sexual transmitted diseases. These, however, fail due to communication gap between relevant government structures and the communities as for example, HIV/AIDS infection keep growing and that the population keeps growing with no overt sign of controlling it should such a dire need exist.

On the other hand, according to the World Population Prospects on www. wikipedia.org (2011), it is estimated that the population of the world will grow to 9 billion by 2040, an increase of 2 billion from the current estimation. South 
African population is estimated to be at 50 million when 2011 census results were released. This indicates the threat of overpopulation which comes with challenges such as competition of limited resources such as sanitation, water, clean environment and poverty in general which Developmental Local Government aims to root out.

In South Africa, most populated areas and in particular those occupied by majority blacks are characterised by poverty due to limited economic activities (Census 2011). The ideas of Developmental Local Government, as stated in the Local Government Turn Around Strategy (LGTAS) developed by COGTA can be achieved through community participation in matters of governance. It will, for example, be difficult for government to coerce community members to take part in reduction of overpopulation when there is still a communication gap between government and its communities. The messages sent out by government also have to be reviewed so as to be correct to address this communication gap.

\section{IMPACT OF POPULATION GROWTH ON DEVELOPMENTAL LOCAL GOVERNMENT}

\section{Population trend in South Africa}

According to the Rural Settlement in South Africa report released in 2001, 22 Million people $(46.3 \%)$ reside in rural areas. It however has to be noted that the country's rural population is not equally distributed over the provinces. Even more critical is the fact that there is skewed distribution of these poor communities within and across all provinces. This has an impact on budget expenditure on rural development per province in areas like infrastructure development, social and economic development.

In the same report, Limpopo is shown as a province with the highest rural proportion as compared to Gauteng Province which has the lowest. Only 3\% of Gauteng's total population is classified as rural. Country-wide, KwaZulu Natal has largest number of rural dwellers at nearly 6 million while Northern Cape has the lowest number of rural dwellers estimated at 500000 people. This suggests that provinces dominated by rural areas are more likely to be poor as poverty and lack of skills is associated to rural areas.

Although developed countries show clear migration pattern from urban centres to rural, developing countries still experience the opposite. Poverty, lack of land, lack of employment and other economic activities drive people to urban areas to eke some living with the hope of supporting and feeding families who live in rural areas. However, this has only served to greatly worsen the migration 
from rural to urban areas without releasable benefits, especially for those left in rural areas. Population growth is accompanied with challenges of scare and limited resources which sometimes result to service delivery protests as communities are frustrated with poor and under-performance of government in this area of service deliver. Realisations of Developmental Local Government is always difficult to achieve because of competition between available resources and demand for service delivery that is able to account for services of its people gets lost when resources stay the same in increased demand.

\section{Effect of human overpopulation}

Overpopulation is generally undesirable condition where an organism's numbers exceed the carrying capacity of its habitat. Overpopulation can result from an increase in birth, decline in mortality rate, an increase in migration or an unsustainable biome and depletion of resources (Overpopulation.Com 2003).

On the other hand, it is also possible for very sparsely populated areas to be overpopulated if the area has meagre or non-existent capability to sustain life. The desert can be a good example for this. The human population has gone through a number of periods of growth since the dawn of civilisation in the Holocene period around 10,000BC. The rate of population growth began to increase at fast rate at the start of industrial revolution about the 18th century. Robert from Cape Town wrote on Times Live on 17 June 2011 that overpopulation is South Africa's major problem which will cause crisis as no one seem to be worried about controlling it.

Human overpopulation therefore will result in strengthened competition for resources such as land, wealth and economic activities. This will result in shortage of resources mostly wanted for survival. Although South Africa's economy is highly rated compared to many countries in Africa, already there are people living in poverty and overpopulation will just worsen the situation as it will result in negative and unproductive competition for already stretched resources. The heading below will discuss challenges of overpopulation on developmental local government.

\section{Challenges of overpopulation on Developmental Local Government}

Overpopulation does not depend only on the size or density of the population but on the ratio of population to available sustainable resources. That is, a function of the way resources are used and distributed throughout the 
population. The resources to be considered when evaluating whether an ecological niche is overpopulated include clean water, clean air, food, shelter, warmth and other resources necessary to sustain life (Overpopulation.com). Other problems associated with or exacerbated by human overpopulation include:

- Soil contamination and noise pollution.

- Deforestation and loss of ecosystem.

- Changes in atmospheric composition.

- Irreversible loss of arable land.

- High infant and child mortality.

- Starvation and malnutrition and

- Unhygienic living conditions.

All of the above mentioned effects of overpopulation are a threat to the notion of the Developmental Local Government and rural development. The next heading explains the importance of effective communication in the realization of goals of developmental Local government.

\section{ROLE OF EFFECTIVE COMMUNICATION IN REALISING THE GOALS OF DEVELOPMENTAL LOCAL GOVERNMENT}

\section{Developmental Local Government}

According to the White Paper on Local Government (1998: Section B\{1\}), Developmental Local Government aims at ensuring that municipalities work together with local communities as an attempt to finding sustainable ways meet their needs and improve the quality of their lives. This is responding to the constitutional mandate that commits government to take reasonable measures within its available resources to ensure that all South Africans have access to adequate housing, health care, education, food, water and social security (Constitution of the Republic of South Africa, Chapter 7). As developmental outcomes of local government, there is a need for community empowerment which will be hard to achieve within challenges of overpopulation where the demand will be more than the supply as more people will compete for limited resources.

Developmental Local Government has the characteristics of maximizing social development and economic growth, integrating, coordinating and democratising development plus leading and teaches community members to 
take active role in matters of governance and development of their living conditions (The White Paper on Local Government, 1998: section B\{2\}). Social development may take different shapes including the use of arts and culture and delivery on aspects of social welfare services. On the other hand, integrating and coordinating involves bringing different developmental agencies together and for the local government to partner with citizens and community groups (The Constitution of the Republic of South Africa 1996, Chapter 7\{152\}).

The White Paper on Local Government (1998: section B\{2\}) also indicates that the Developmental Local Government will achieve its goals through taking local citizens as partners in matters of governance including policy development. This, however, demands for effective communication which has proved to be lacking in different parts of the world. The Integrated Sustainable Rural Development Strategy (ISRDS)(2000: Sections 5 and 6, pages 24 - 37) echoes the sentiments that there is a need for effective communication and information dissemination for integrated rural development through consultative processes. It is argued here that the consultative process will allow rural people to express their goals and priorities which will add quality on the resulting decision.

The above strategy indicates the importance of stakeholder mobilisation. Both the ISRDS and the White Paper on Local Government (1998, section B\{2\}) identified the need for effective communication between local government and communities but failed to come up with the framework for effective communication.

\section{Legal obligations of Developmental Local Government - the South African situation}

According to the Constitution of the Republic of South Africa, 1996, (Chapter $7\{152\})$ local government has to provide democratic and accountable government for communities. This sphere of government also has to promote social and economic development which is the anchor of rural development. What is important is that the local government has to encourage the involvement of community and community organizations in matters of local governance through effective communication.

According to Olutimayin (2002:237) local government, with special reference to districts and the local municipality, will achieve the goal of involvement of communities only through effective communication. This includes the use of media, meetings such as the Integrated Development Plan (IDP) consultations, council meetings and general outreach programmes. The Government also 
established the Batho-Pele Principles (putting people first) to be applied when government institutions are dealing with community members. However, communication needs to be taken to the level of Ward Committees.

The Batho Principles and the White Paper on local Government (1998: section $B\{2\})$ need people to be consulted on level and quality of services they receive from government. Community members also have to get access to services they are entitled to by involving them on governance matters. One of the Batho-Pele principles requires that community members be given full and accurate information in an open and transparent environment. This suggests that they have to know exactly the impact of overpopulation on their lives and their environment so that they start coming up with or supporting intervention mechanism

The Batho-Pele principles also emphasised the need for improved and strengthened communication between the local government and rural communities. The ISRDS (1999:24) also emphasises the need for local government to strengthen stakeholder mobilization. Like in the case of community communication above, the ISRDS does not provide the relevant framework for stakeholders' mobilisation.

\section{Role of Effective Communication in Developmental Local Government}

What then is Effective Communication for Rural Development? Effective Communication for Rural Development and enhancement on Developmental Local Government refers to communication characterised by community participation where in community members are empowered with information and are part of the identification of their needs, challenges, intervention plans, implementation thereof, evaluation and monitoring in an environment conducive for them to take issues of development into their own hands by becoming active participants and owners of the whole process. This means that members of the community are persuaded to take matters of their development serious including putting control on catalysts of overpopulation.

\section{INVOLVING THE COMMUNITY MEMBERS}

It is only when community members are becoming active participants in governance and in matters of development that they will also contribute. Active community members can for example participate in all matters that can push the frontiers of overpopulation at bay such as control on birth and instigations of migration. This, according to Larson (1990:165) and O'Keefe (2002:2), happens 
only when there is effective communication that can persuade community members towards taking matters of own development into their own hands.

Berberet (2003: 94) argues that there is a need for institutions within the communities such as the municipalities to focus on involving community members in their activities. Berberet (2003: 91) was arguing for American institutions of higher education to start avoiding working for themselves only but the communities. This is what local government has to do to encourage participation by rural communities in matters of development and this may be achieved through effective communication.

Local government should construct an epistemology for communication of community engagement that requires both rethinking of the level of participation of rural community members in matters development. As Berberet (2003:94) continues to argue, community engagement requires holistic perspective and role modelling responsibilities. Government needs to strengthen its communication with communities by improving interaction and develop communication skills of local structures such as the Ward Committees (A Handbook for municipal Councillors 2011:164).

There is therefore a need for a model for effective communication between the local government and rural communities which will see community members getting engaged and involved in matters of governance and matters of development such as the fight against overpopulation. The current IDP consultation and government outreach programmes are more on consulting and mobilizing community members but fail to sustain working relationship and community full participation. In this regard, communication will be performing a role of being a development catalyst. Local communication structures, if empowered with skills and insight will be able to communicate messages to the communities in a more relaxed and conducive situation as it will be happening right where they stay. There is a need for effective communication model as proposed below which will take members of the community on board in activities of development even beyond just matters of population control.

\section{A MODEL FOR EFFECTIVE COMMUNICATION AIMED AT PROMOTION OF DEVELOPMENTAL LOCAL GOVERNMENT AND RURAL DEVELOPMENT}

As per the White Paper on Local Government (1998: Section B), to enhance communication for effective Developmental Local Government in rural communities, it is suggested that there be an establishment of a communication framework or model that will suit and encourage the realisation of the objectives of the Developmental Local Government which include harnessing full citizen 
participation in matters of governance and development. The new model of effective communication between local government (municipalities) and rural communities is aimed at bridging the communication gap experienced when using existing linear models where the sender of the message and recipient do not operate as equal participants in their communication

It should also be able to create more understanding, belief and a sense of togetherness between government and municipalities as message senders and the rural community members as active recipients. Challenges of overpopulation cannot be controlled by the imposition of policies by government but by community understanding and buy-in.

This model will be able to create mutual understanding between the government local government and rural communities and be able to create a sense of self-realisation and make community members to take up matters of development. As argued by Berberet (2003:94), states that the model should be able to have holistic perspective and role-modelling responsibilities. The model should be based on community-based-planning as it has to involve rural community members from the beginning of each communication process until the end. Local Government should find ways through which the message is first shared with community members through active participation. At the end of the process, both the Local Government and the rural community members should have mutual understanding on service delivery processes and together accept joint accountability in dealing with challenges of overpopulation (Kinder 1998:2).

\section{CONCLUSION}

There are several mitigation measures that can be applied to reduce the adverse impact of overpopulation through effective communication. These mitigations are ways to implement social norms as overpopulation is an issue that threatens the state of the environment and community participation in matters of their development. While in other countries like China the government puts policies to control number of children per couple, there is a need to get community buyin to initiatives against overpopulation through effective communication. 


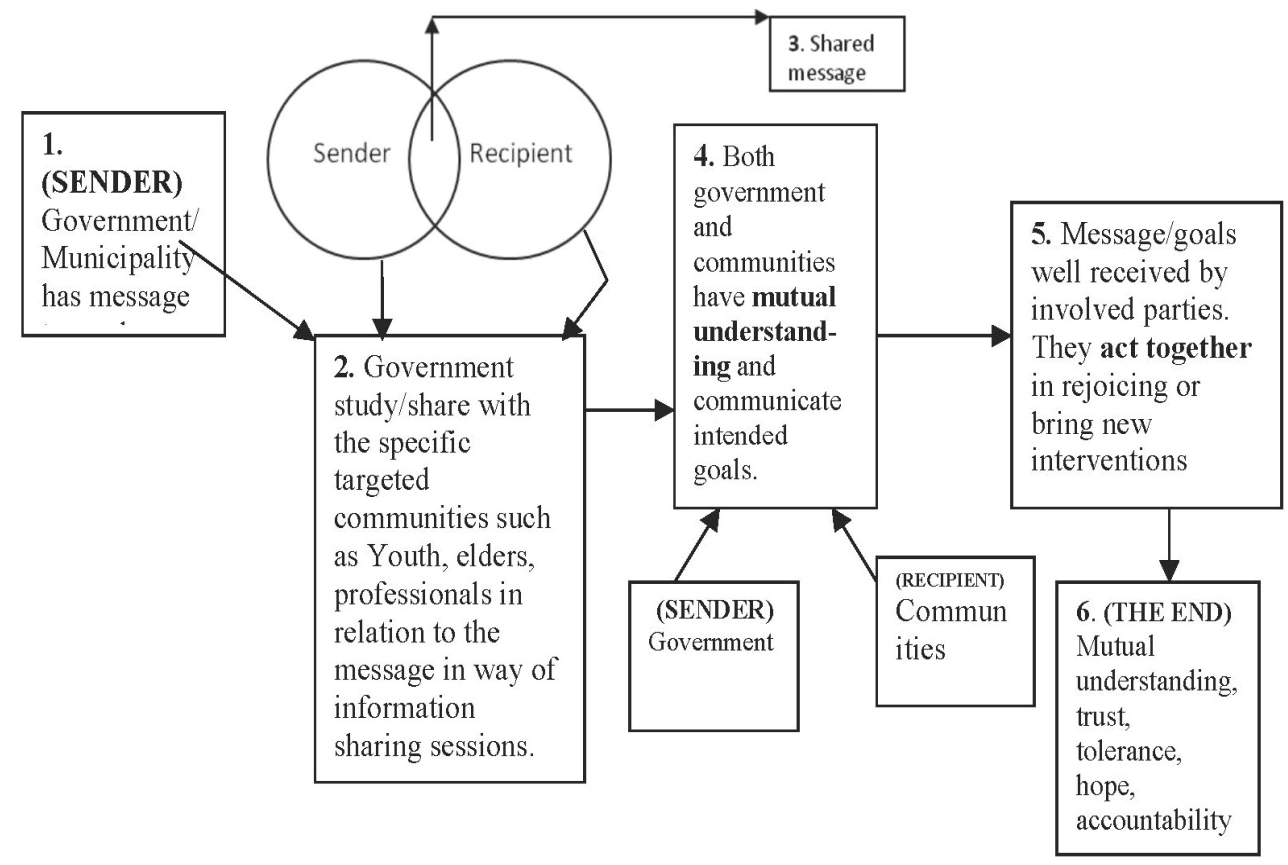

Figure 1: A proposed model for effective communication to enhance Developmental Local Government for rural development amid challenges of overpopulation

Community members should be made aware of the ideas behind Developmental Local Government which demands of Local Government to strengthen their strategies to make sure community members become part of government planning and that these policies are not imposed. Beyond the usage of brochures, mass media such as radio and television there is a need to introduce a communication model and strategies that brings community members on board from the stage of policy formulation, to implementation and to the monitoring and evaluation of these policies so as to create the sense of ownership as in the proposed model for effective communication for rural development advocated in this paper. The interaction with communities should happen in all community places such as places of worship, shebeens, schools, stadium, shopping centres and family homes.

The proposed model of communication functions even better where the situation allows communication to be taken to the Ward Committee level. Ward Committee members should be trained in developmental communication. They 
need to be made aware of the best ways of communicating matters of health reproduction, protective sex and reasons behind the practice. The Ward Committee operates right at the community level. When allocating portfolios for members of the Ward Committee, the Ward Councillor who leads the ward Committee should also have one member focusing on matters of communication as a portfolio. This member should also seat in communication structures or forums of the Local Municipality. This member is also expected to report on communication matters to the monthly Ward Committee meetings and also establish communication platforms comprised of community structures such as the Civic Association, traditional leadership councils, local education sector, local Community development workers (CDW) and other relevant structures such as churches and forums of special focus such as those for youth, disabilities and women. The CDW should play a major role of providing secretariat work as they are based at local level and are resourced as they receive salaries, having cellular phones and laptops. Ward committee members do not enjoy these benefits.

This forum at the local level will discuss local communication matters and also report to local communities on plans of the local municipality in building sustainable livelihood. Matters under discussion will include those dealing with universal access to health services. Those who are custodians of cultural behaviours should also be involved when developmental issues on health reproduction and other related topics are addressed so as to get their buy-in.

\section{List of References}

- A handbook for Municipal Councillors (2011) SALGA, Waterkloof, South Africa.

- Berberet, J. (2003) Nurturing an Ethos of Community Engagement: EBSCO Publishing.

- Bowes, J.E. (1997) Communication and community development for health information: Constructs and models for evaluation, www.nlm.nih.gov/pnr/ eval/bowes

- Dudley, L (1999) Communication and Economic Growth. European Economic Growth Review 43 (1999) pp 595-619. Elsevier Science BV 
- Hurskainen, A (1993) Knowledge or Prejudice? Bridging the Communication Gap between Centre and periphery: University of Helsinki, Finland

- Kinder, C (1998) The population Explosion: Causes and Consequences: New Haven Teachers Institute, www.yale.edu/ny/ynhti/curriculum/ units/1998/7/98.07.02.x.html

- Larson, C. U. (1990) Persuasion, Reception and responsibility: Wadswort Publishers

- Lu,Y (2009) Challenges for China's international Communication: University of Nottingham, UK

- O'Keefe, D.J. (2002) Persuasion, Theory and Research: University of UrbanaChampaign: SAGE.

- Olutimayin, J (2002) Communication in Health Care delivery in developing Countries. Which way Out? The University of the South Pacific, SUVA

- "Overpopulation is a South Africa's Major Problem" Times Live , 17 June 2011

- Sawer, M (2009) Bridging the gap between government and the people. http:www. federationpress.com

- South Africa's population continued to grow despite the Aids crises 9 http://www. overpopulation.com/articles/2003

- State of Local Government in South Africa (2009): Department of Cooperative Governance \& Traditional Affairs (COGTA), Pretoria, South Africa

- The White Paper on Local Government (1999). Department of Provincial Affairs and Constitutional Development, SA

- "World population prospects" (http:/www.un.org/popin/)[ 47 ]

\section{AUTHORS' CONTACTS:}

\section{B.N. Rasila}

University of Venda

Email: rasilan@premier.limpopo.gov.za

\section{M.J. Mudau}

University of Venda,

Centre for Rural Development and Poverty Alleviation.

Email: john.Mudau@univen.ac.za 